\title{
HERV-K(HML-2), the best preserved family of HERVs: endogenization, expression, and implications in health and disease
}

\section{Oliver Hohn, Kirsten Hanke and Norbert Bannert*}

Division for HIV and Other Retroviruses, Robert Koch Institute, Berlin, Germany

\section{Edited by:}

lyoko Katoh, University of Yamanashi, Japan

Reviewed by:

Holger Kalthoff, Institute for

Experimental Cancer Research,

Germany

Shashidhar Jatiani, Forest Research

Institute, USA

${ }^{*}$ Correspondence:

Norbert Bannert, Division for HIV and

Other Retroviruses, Robert Koch

Institute, Nordufer 20, 13353 Berlin,

Germany

e-mail: bannertn@rki.de
Retroviruses that have the ability to infect germ line cells can become an integral and inherited part of the host genome. About $8 \%$ of the human chromosomal DNA consists of sequences derived from infections by retroviruses that presumably circulated 2-40 millions of years ago, and some elements are actually much older. Post-insertional recombinations, deletions, and mutations have rendered all known human endogenous retroviruses (HERVs) non-infectious. However some, particularly the most recently acquired proviruses of the HERV-K(HML-2) family, can expresses viral proteins and produce viral particles. In this review we will first discuss the major aspects of the endogenization process and peculiarities of the different HERV-K families. We will then focus on the genes and proteins encoded by HERV-K(HML-2) as well as inactivation of these proviruses by postinsertional mutations and their inhibition by antiretroviral factors. After describing the evolutionary interplay between host and endogenous retrovirus we will delve deeper into the currently limited understanding of HERV-K and its possible association with disease, particularly tumorigenesis.

Keywords: human endogenous retrovirus, HERV-K, replication, Rec, cancer

\section{INTRODUCTION}

Human chromosomes contain numerous retroviral sequences that form part of our genetic legacy. In total, human endogenous retroviruses (HERVs) sequences account for $\sim 8 \%$ of our genome. With more than 500,000 elements, there are over 20 -fold more HERV sequences than there are human genes. These elements typically have their origin in ancient infections of germ cells by exogenous retroviruses that circulated $\sim 2-40$ million years ago. The human genome and the genomes of other vertebrate species that contain endogenous retroviruses can therefore be regarded as museums of ancient retroviruses. Phylogenetic studies have allowed these elements to be sorted into distinct groups that are usually termed "families." Similar to artifacts in an archeological museum, time has left its traces on these retroviral elements and very often only "shards" of the once complete sequence remain. All known proviruses in the human genome have suffered from postinsertional mutations, deletions, and recombinations that render them non-infectious. Most often, only a single long terminal repeat (LTR) remained. In contrast to humans, several other species including mice and sheep carry infectious endogenous retroviruses $(1-3)$.

The most recently integrated and best preserved human proviruses belong to a subgroup of the HERV-K elements dubbed HERV-K(HML-2). The HERV-K group can be divided into 10 families (4). The designation " $K$ " comes from their use of a lysine tRNA to prime reverse transcription and human mouse mammary tumor virus like-2 (HML-2) indicates their relationship to the murine betaretrovirus mouse mammary tumor virus (MMTV). More than 90 proviruses of the HML-2 family are exceptionally well preserved and maintain open reading frames encoding functional viral proteins (4). These proteins are expressed and noninfectious particles are released in various cells, particularly in tumors and cancer cell lines derived from teratocarcinomas and melanomas (5-7). Moreover, two research groups have demonstrated that consensus sequences of HERV-K(HML-2) elements are able to produce infectious particles $(8,9)$. The infection and replication of these particles is inhibited by a variety of restriction factors including members of the APOBEC family, tetherin and most likely other, yet to be identified antiviral factors that have evolved over millions of years of coevolution between this virus and its primate hosts.

HERV-K proviruses can be classified into two types. Only type II proviruses express the accessory Rec protein that functionally resembles the HIV Rev and HTLV Rex proteins (10, 11). Type I proviruses have a 292-bp deletion that prevents expression of the rec gene but can instead express an alternative protein called $\mathrm{Np} 9$. Both $\mathrm{Rec}$ and $\mathrm{Np} 9$ are associated with malignancies. In addition to the evidence for the protein-induced or promoted tumorigenesis of somatic cells, HERV-K elements are also implicated in cancer development at the DNA or RNA level. In this context, HERV$\mathrm{K}$ proviruses have been shown to be involved in recombination events that in one setting left an LTR-promoter closely upstream of exons 5-12 of the ETV1 gene that encodes a transcription factor of the Ets family. Androgen-dependent expression of the protein fragment driven by the viral LTR was correlated with an increase in the invasiveness of prostate cancer (12). Promoters of other HERV elements and retrotransposons have also been shown to stimulate expression of nearby genes that promote malignancy (13). The 
number of known genes that are under definite transcriptional control by HERVs and our understanding of the mechanisms involved have dramatically increased in recent years (14).

In this regard it should be stressed that transcription of HERV$\mathrm{K}$ and other HERV elements is usually suppressed by epigenetic factors such as DNA methylation and heterochromatin-silencing by histone modifications (15). Nevertheless, it is estimated that even in normal healthy cells, retroviral LTRs initiate 10 times as many transcripts as regular promoters (16-19). The transcripts induced include many RNAs that are complementary to regular gene transcripts and can downregulate the expression of cellular genes (17). During tumorigenesis (and also, presumably, in other poorly understood situations) this epigenetic control can be partially or selectively weakened and particular retroviral promoters become able to vigorously activate the transcription of cellular genes.

\section{ENDOGENIZATION OF RETROVIRUSES WITH A FOCUS ON HERV-K(HML-2)}

The prerequisite for acquisition of a new endogenous retrovirus is infection of a germ line cell that results in integration of the proviral DNA into the cell's chromosomal DNA. If this integration and the possible replication of this founder virus do not prevent fertilization, a fetus can form that carries the retroviral element in every one of its somatic and germ line cells. From a genetic perspective, the provirus becomes a regular host gene that is passed down the generations, being inherited in a Mendelian fashion (20-22). Such endogenization and transfer to offspring has been demonstrated in the laboratory by infection of fertilized eggs with recombinant avian leucosis virus (23). The viremia in the carriers can be attributed to replication of either the exogenous or the endogenous form, which results in repeated infection of somatic cells. It can be assumed that frequent recombination events occur at that stage by copackaging of vRNAs, one from an inherited endogenous element and one from an infecting exogenous virus with template switching by the reverse transcriptase (RT) occurring during subsequent infection of a new host cell. To some degree, germ cells might also be repeatedly infected, leading to further colonization of the germ line and amplification of the number of viral elements belonging to the same family. Other modes of amplification are also conceivable and have been documented, including retrotransposition or duplication of chromosomal regions that contain HERV elements (24). However, in the case of HERV-K(HML-2) it appears that the predominant mode of amplification within the human genome has been reinfection by circulating infectious viruses over a period of at least 30-40 million years (25). Colonization of the human genome by this betaretrovirus did not occur at the same frequency all the time: there were bursts of integration, during which the replicative activity of the virus is assumed to have been high, interspaced with longer periods of low integration (25). In recent years the number of known human-specific HERV-K(HML-2) loci has risen $(4,10,26)$ and the lack of these loci in chimpanzees, our closest primate relatives, proves that elements of this family continued to reinfect our ancestors after their split from the chimpanzee lineage about five to six million years ago. Although there is no evidence for it being ongoing in humans, retroviral integration is not something that only occurred in the distant past. In Australia we are currently witnessing a fulminant endogenization process in koala bears involving a retrovirus presumed to have been acquired from a species of Asian mouse only a hundred or so years ago (27-29).

The reproductive success of individuals carrying a germ line provirus at a particular chromosomal locus determines the frequency of this element in the population, i.e., it is subject to host selection (Figure 1). Selective forces and fluctuations in the population size (first and foremost bottlenecks that simply by chance increase the relative ratio of the carriers in the population) might eventually result in fixation of the element. This means it is present in all members of the population. It can be inferred that the likelihood of an element reaching fixation correlates negatively with its virulence if it compromises the reproductive success of the carrier. It is therefore likely that neutral elements or elements that even endow the carrier with a selective advantage are more likely to reach fixation whereas those with a negative impact will not and will eventually vanish. One piece of solid evidence in favor of this hypothesis is the orientation of the endogenous elements found in introns. Although integration has no preference with regard to direction, the majority of HERVs have an orientation opposite to that of the gene they have integrated next to, usually rendering the splice sites and other regulatory elements inactive. Elements that occurred in the same orientation as the gene vanished with higher frequency because they can modify expression of the encoded cellular protein to the detriment of the host. In contrast, there are only very few elements that are obviously under strong positive selective pressure, none of which belong to the HERV-K(HML-2) family (30).

\section{HERV-K FAMILIES}

To date, there is little known about members of the HERVK superfamily other than HERV-K(HML-2). All HML families belong to the class II/betaretrovirus group, which also contain the endogenous and exogenous MMTV, Mason-Pfizer monkey virus (MPMV), and Jaagsiekte sheep retrovirus (JSRV) (31). Elements such as HML-4 and HML-6, which are related to but clearly distinct from the HERV-K(HML-2) prototype virus HERV-K10 (32), were identified more than 20 years ago by extensive lab work using low-stringency Southern blot analyses with MMTVderived $\mathrm{gag} / \mathrm{pol}$ probes (33). These data were later complemented by PCR and the sequences were grouped into the HERV-K families HML-1 to HML-6, based on the sequences of a conserved RT region (34). These results were subsequently compiled to yield our current understanding that there are up to $10 \mathrm{HERV}-\mathrm{K}(\mathrm{HML})$ families in addition to a related family HERV-K(14C) present in the human genome (35). As the complete human genome has now been sequenced, identification of HERV elements can now be performed with relative ease by database analyses. Searching for sequences derived from the cloned HERV-K (HML-1 to HML-10) elements reveals a probable total of about $550 \mathrm{HERV}-\mathrm{K}$ proviruses and 6400 solitary LTRs in the human genome (36), ranging from $150 \mathrm{HML}-3$ proviral elements to $5 \mathrm{HML}-4$ proviruses, for example $(24,37)$. Not all HML families are described in detail using in silico generated consensus sequences or by analysis of individual elements, a summary of the features of HERV-K families is given in Table 1, although these numbers may need to be revised as was recently done for HML-2 solo LTRs, being adjusted from $\sim 2500$ to $944(4,38)$. 


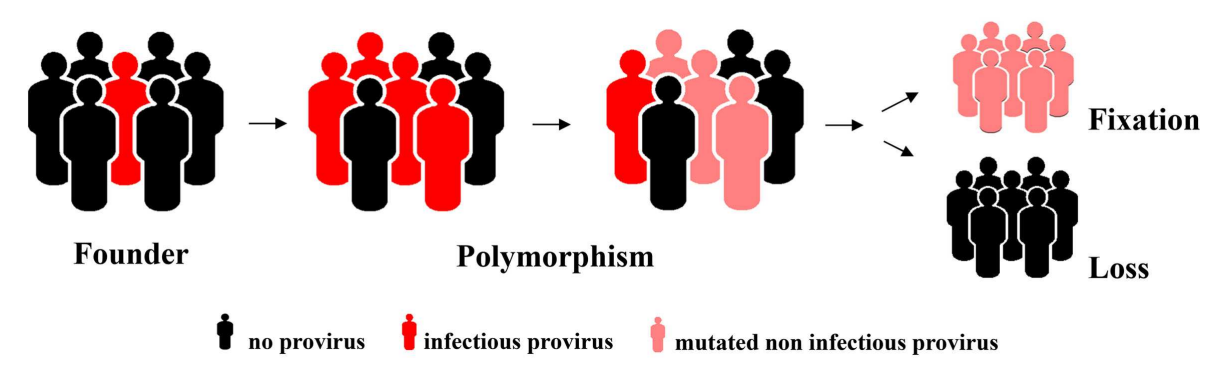

FIGURE 1 | Hypothetical model for an increase in allelic frequency and eventual loss or fixation of an endogenized element integrated at a particular chromosomal locus.

Table 1 | Class II/HERV-K (human MMTV-like) families.

\begin{tabular}{|c|c|c|c|c|c|}
\hline \multirow[t]{2}{*}{ Name } & \multirow[t]{2}{*}{ Alternative names } & \multirow[t]{2}{*}{$\begin{array}{l}\text { Estimated time of } \\
\text { integration (mya) }\end{array}$} & \multicolumn{2}{|c|}{$\begin{array}{l}\text { Estimated copy number } \\
\text { in genome }\end{array}$} & \multirow[t]{2}{*}{ Reference } \\
\hline & & & Proviruses & Solo LTRs* & \\
\hline HML-1 & NMWV6, HERV-K14I & $\sim 39$ & 68 & 350 & $\begin{array}{l}\text { Franklin et al. (33), Medstrand and Blomberg (34), Flockerzi } \\
\text { et al. (41) }\end{array}$ \\
\hline HML-2 & NMWV1, HDTV & $\sim 35-2$ & 91 & 944 & Subramanian et al. (4), Bannert and Kurth (24), Ono (42) \\
\hline HML-3 & NMWV5, HERV-K9l & $\sim 36$ & 140 & 700 & $\begin{array}{l}\text { Franklin et al. (33), Medstrand and Blomberg (34), Mayer } \\
\text { and Meese (43) }\end{array}$ \\
\hline HML-4 & HERVK13I, HERV-K-T47D & $\sim 55-35$ & 5 & 800 & Medstrand and Blomberg (34), Seifarth et al. (37) \\
\hline HML-5 & NMWV2, HERV-K22I & $\sim 55$ & 139 & 600 & Franklin et al. (33), Lavie et al. (40) \\
\hline HML-6 & NMWV4, HERV-K3I & $\sim 30$ & $30-40$ & 50 & Franklin et al. (33), Medstrand et al. (44), Yin et al. (45) \\
\hline HML-7 & NMWV7, HERV-K11D1 & n.d. & 20 & 140 & Franklin et al. (33), Andersson et al. (35) \\
\hline HML-8 & NMWV3, HERV-K11I & n.d. & 60 & 600 & Franklin et al. (33), Andersson et al. (35) \\
\hline HML-9 & NMWV9 & n.d. & 10 & 40 & Franklin et al. (33), Andersson et al. (35) \\
\hline HML-10 & HERV-K(C4) & $\sim 30$ & $10-50$ & 100 & Jern et al. (31), Tassabehji et al. (46) \\
\hline
\end{tabular}

*Most copy numbers of solo LTRs given in Ref (24); mya, million years ago; n.d., not determined.

The oldest group within the HERV-K superfamily appears to be the HERV-K(HML-5) family. Based on the traditional criterion for naming the HERV elements, HML-5 proviruses could constitute the HERV-M family, as the primer binding site of the consensus sequence is identical to the $3^{\prime}$ end of methionine tRNA. These elements are not found in prosimians, and are the only HERV-K proviruses in both Old World and New World monkeys, suggesting that the integration event must have taken place 35-55 million years ago. An even more precise estimate for the time of integration can be made by examining the LTRs. At that point in time, both LTRs in the viral genome would have been identical, but in the host genome they would accumulate random mutations at a rate of $2.3-5 \times 10^{-9}$ substitutions per site per year (39), i.e., one difference between the two LTRs would be generated every 200,000-450,000 years. Although this kind of estimation has several limitations, including the fact that there were certainly periods of varying mutational rates, the integration of HML-5, based on LTR-LTR divergence, is estimated to have occurred $\sim 55$ million years ago. It is interesting to speculate whether the age of HML-5 makes it the ancestor of other HERV-K families. However, sequence comparisons show that HML-5 does not lie at the root of the
HERV-K phylogenetic tree, suggesting that this is probably not the case (40).

Remarkably, within the HML-1 family seven proviruses were found in which gag, pro, and pol sequences have been replaced by similar regions from HERV-W, resulting in hybrid structures (41). Such recombination events can occur by template switching by RT or at the DNA level. However, the differing flanking cellular sequences indicate that at some point the initial hybrid provirus was able to form progeny proviruses in the genome through a transcript.

\section{HERV GENES, TRANSCRIPTS, PROTEINS, AND STRUCTURE}

To varying degrees, endogenous retroviruses are phylogenetically similar to exogenous retroviruses and it is therefore common to categorize them into three different classes. While class I HERV elements (e.g., HERV-W, HERV-FRD) have similarities to exogenous gammaretroviruses (e.g., MLV, GaLV) and class III HERV (e.g., HERV-L) are distantly related to lenti- or spumalike retroviruses (e.g., HFV), the structure of a HERV-K(HML-1 to HML-10) element resembles a typical betaretrovirus (31). As HERV-K(HML-2) elements, in addition to the four major ORFs for gag, pro, pol, and env, also encode an accessory gene similar to 
those of delta-, lenti-, and spumaviruses they were defined as complex endogenous retroviruses. HML-2 type II proviruses encode an HIV-1 Rev- or HTLV-1 Rex-like protein termed Rec and only $26 \%$ of HML-2 elements are classified as type I expressing the protein $\mathrm{Np} 9(4,47,48)$. The genomic organization of these proviruses and their resulting RNA transcripts are shown in Figure 2.

The full-length HML-2 mRNA encodes the structural proteins of Gag, termed matrix (MA, p15), capsid (CA, p27), nucleocapsid (NC, p10) plus three smaller peptides as well as the putative phosphoprotein (pp15) (49). Due to two slippery sites and the resulting -1 bp ribosomal frameshifts, the Gag-Pro and Gag-Pro-Pol precursor proteins are produced and processed into the protease (Pro) enzyme and into polymerase ( $\mathrm{Pol})$ that exhibits RT and integrase (IN) activity. The single spliced mRNA for Env encodes the typical retroviral Env protein consisting of a signal peptide, a surface unit (SU; $\sim 44 \mathrm{kDa}$ ), and a transmembrane unit (TM; $\sim 26 \mathrm{kDa}$ ). A functional Env protein has only been described for the HERVK108 provirus (50), although the infectivity of another HERVK(HML-2) element (K113) could be restored by back mutation of putative post-insertional amino acid changes (51). In addition to another two mRNAs coding for the accessory proteins Rec or Np9 that will be addressed in detail later, a $1.5-\mathrm{kb}$ transcript termed hel has been found in human teratocarcinoma cell lines (48) although, as this mRNA does not encode a protein, its function requires clarification.

Some exogenous and endogenous retroviruses code for a dUTPase in addition to the enzymes essential for the retroviral life cycle such as RT, RNase H, Pro, and IN. dUTPase catalyzes the degradation of dUTP in order to prevent the toxic misincorporation of uracil into the newly forming proviral DNA. Both betaretroviruses and non-primate lentiviruses [i.e., Maedi-Visna virus (MVV) and equine infectious anemia virus (EIAV)] feature a dUTPase, albeit located in different regions of the genome $(31,52)$. The dUTPase in betaretroviruses is found within the N-terminal region of pro whereas in non-primate lentiviruses it is in pol.

\section{POSTINTEGRATIONAL MUTATIONS AND REPLICATION POTENTIAL OF HERV-K}

It can be assumed that unless antiretroviral cellular factors of the APOBEC-superfamily were deaminating their genomes during reverse transcription, the majority of HERV-K(HML-2) elements were replication competent for some period of time after integration into the germ line cell genome. HERV-K(HML-2) is particularly susceptible to APOBEC $3 \mathrm{~F}$ and APOBEC $3 \mathrm{G}$ deamination as shown in infectivity assays using infectious viruses produced with HERV-K(HML-2) consensus sequences $(9,53)$. Moreover, 2 of 16 (53) most recently integrated elements known are substantially mutated by APOBEC deaminases, indicating that these antiviral factors were already active several millions of years ago. How long elements that escape restriction by deaminases are usually able to produce infectious viruses is an open question. It is known that some endogenous retroviruses of pigs, sheep, and other animals have resided in their host's genomes for tens or even hundreds of thousands of years and yet retain open reading frames and remain both replication competent and infectious (21). Some replication competent porcine endogenous retroviruses in Old World pig species are presumably even older (3).

It is known that during their residency in the host cell genome, endogenous elements acquire postinsertional mutations and deletions that can inactivate the provirus. Recombination events frequently take place that delete most of the proviral sequence, leaving just an LTR (solo LTR). With HERV-K, solo LTRs outnumber elements still framed by both LTRs by a factor of at least 10. In contrast to these single LTR remnants, HERV-K(HML-2) proviruses also exist that possess open reading frames for all viral genes. Such elements include variants (haplotypes) of HERV-K113 and HERV-K108 that are thought to be two of the most recently acquired elements $(4,26)$. However, post-insertional mutations other than those that generate premature stop codons have since rendered these viruses replication incompetent $(36,54)$ : infection could not be achieved using supernatants from germ line cells that

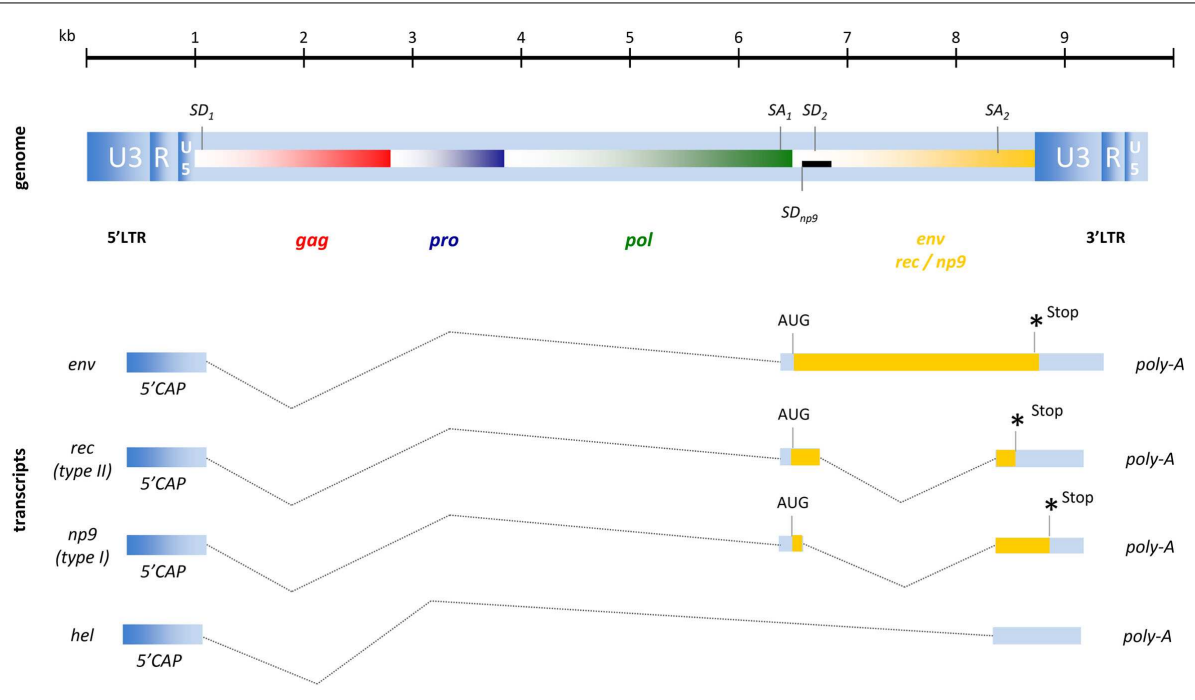

FIGURE 2 | Proviral organization of HERV-K(HML-2) and RNA transcripts. The black bar represents a 292-bp deletion that results in the Np9 gene product for type I proviruses instead of the Rec (an HIV-1 Rev homolog) characteristic of the type II proviruses. Hel is a poorly described RNA without protein coding function. 
release HERV-K(HML-2) particles. Indeed, none of the currently known HERV-K(HML-2) elements appear to have the capacity to produce infectious particles. It is not known when the most recent HERV-K(HML-2) endogenization occurred and when the last provirus lost its ability to replicate. In fact, although unlikely, the existence of an infectious HERV-K(HML-2) provirus with low prevalence in the current human population cannot be completely ruled out.

Even if no functional HERV-K(HML-2) element is currently extant in humans, an infectious virus might nevertheless be reborn as a chimera of partially inactivated parental elements. That infectious retroviruses can form by recombination between the RNA genomes of two inactivated parental elements is well documented, with the two most recent occasions involving murine gammaretroviruses, including the notorious XMRV $(55,56)$. Similar events could also result in the reconstitution of a replication competent HERV-K(HML-2) element. Indeed, Heidmann and Co-workers have demonstrated in vitro the reconstitution of an infectious HERV-K(HML-2) element through recombination of three HERV-K(HML-2) elements (8). Compared to exogenous retroviruses, the infectivity of such reconstituted particles is rather poor and productive replication in cell culture has yet to be demonstrated. It is therefore likely that despite the demonstration of in vitro infection and integration, restriction factors including APOBEC have evolved to prevent productive replication in cell culture and in vivo. However, HERV-K(HML-2) does not appear to be a target of human Trim5alpha, an antiretroviral factor attacking the capsids of infecting retroviruses (9).

\section{ROLE OF HERV-K IN HUMAN EVOLUTION AND PHYSIOLOGY}

In addition to the examples described in more detail below, transposable elements, including HERVs, generally drive alterations of the human genome by providing RT, an enzyme that can facilitate gene duplication for example, and by the addition or modulation of promoter activities. Even before the human genome was sequenced, it was suggested that constant updating of the transcriptional pattern through evolution of cis-acting elements might contribute more to species diversity than do changes in coding regions themselves (57). The simple insertion of an LTR can replace the original promoter, alter tissue specificity, or add enhancer activity (16). Of course, the LTRs acting as mobile genomic elements originate from full-length, inserted retroviruses.

Hypothetically, there are three possible outcomes of retroviral host genome invasion, i.e., genetic modification by the foreign DNA and/or the impact at the specific point of integration can be beneficial, harmful, or neutral for the individual. Retroviral integrations that severely harm the host genome, for example by interfering with the regulation of gene expression through promoter activity or direct destruction of coding regions, cannot play a significant role in human evolution because affected individuals are subject to negative selection and are removed from the gene pool. On the other hand, positive effects of altered gene expression through retroviral integration are well known. For example, the amylase gene is expressed in the pancreas of all mammalian species. However, in primates, rodents, and lagomorphs (rabbits, hares, and pikas), amylase is also expressed in the salivary gland as a result of gene duplication and insertion of a retroviral sequence
(58), an event that probably helped these species to include starch in their diets.

Perhaps the most striking example of mammalian exploitation of retroviral sequences is the co-option of an endogenous retrovirus envelope gene to form the syncytiotrophoblast during pregnancy. The main function of the retroviral envelope protein is to mediate fusion of virus and target cell membranes during infection, making it an ideal "tool" to facilitate cell-cell fusion. The HERV-W (59) and HERV-FRD (60) glycoproteins, expressed exclusively in the placenta, are therefore termed syncytin-1 and -2, respectively. Furthermore, the envelope proteins are involved in retrovirus-induced immunosuppression (61) and as the placenta, as far as the mother's immune system is concerned, is an allogeneic organ, local immunological tolerance is necessary to prevent rejection of the fetus. This capacity for immunosuppression, shown for syncytin-2, but so far not for syncytin-1 (59), may therefore be another reason that the endogenous retroviral env is expressed in the human placenta.

Further evidence for the deliberate co-option of retroviral genes during host evolution includes the presence of syncytin- $A$ and $-B$ genes in the murine genome, genes that have the same functions as their human counterparts but are clearly distinct at the sequence level (62). With mice it is possible to directly study the impact of these genes and "knocking out" syncytin-A results in disrupted placental architecture and the in utero death of embryos (63). The later discovery of syncytin genes in other mammals demonstrates that the exploitation of retroviral env genes has occurred independently and on multiple occasions throughout mammalian evolution. It is exciting to speculate that the first retroviral env integration in an oviparous species marked the beginning of the change from egg-laying prototherians to placental mammals (64).

A more direct advantage for the host of endogenization may be protection from infection by related exogenous pathogenic retroviruses. One well-studied example of this is sheep that carry an endogenous form of JSRV and are therefore protected against infection by exogenous JSRV (65) through receptor interference by the endogenous retroviral envelope. Furthermore, the Gag protein of defective transdominant endogenous JSRV interferes at a late stage of replication with the exogenous form of the protein (66), a phenomenon also described in mice in which expression of an endogenous retroviral Gag protein with homology to the HERV-L family blocks various strains of exogenous MLV (67). To date, no comparable function for HERV-derived proteins is known, but it is very plausible that the open reading frames retained for some HERVs serve a similar purpose.

\section{EXPRESSION AND REACTIVATION OF HERV-K LOCI IN HEALTH AND DISEASE}

Although HERV-K(HML-2) gene expression is largely repressed in most cells by epigenetic silencing, low-level expression occurs in some tissues. Various groups have found that between 7 and $30 \%$ of all HERV sequences in the genome are transcriptionally active $(18,68,69)$. In particular, the testes and placenta appear to be privileged tissues for HERV expression (69). There is an ongoing and active debate about HERV expression in healthy tissues, with some authors assuming a possible advantage for cells that express HERVK proteins (70). Expression of the HERV-K envelope protein TM 
subunit in placental cytotrophoblast cells suggests its potential involvement in placentogenesis and pregnancy (71), as discussed above for syncytin-1 and -2. Moreover, Wang-Johanning and Colleagues have detected low-level expression of HERV-K env mRNAs and proteins in healthy ovarian tissues (72).

Andersson and Colleagues made the very interesting discovery of HERV-K rec transcripts in the placenta and in various other normal human fetal tissues, suggesting that this small RNA transport molecule may play a role in the development and differentiation of human tissues (73).

Although HERV-K is expressed at only very low levels (if at all) in healthy tissues, activation of transcription, and protein production is associated with diseases such as cancer and autoimmune disorders. Indeed, the possible role played by upregulation of HERV-K expression in autoimmune diseases such as multiple sclerosis (MS) and rheumatoid arthritis (RA) is being investigated.

Rheumatoid arthritis is a chronic, systemic inflammatory disorder that especially affects synovial joints. Serological and molecular assays show a significant increase of HERV-K gag expression in RA patients compared to inflammatory and healthy control groups (74). Furthermore, exogenous viral protein expression and proinflammatory cytokines enhance HERV-K gag transcription. Finally, anti-HERV-K antibodies with possible cross-reactivity to host proteins could cause autoimmune responses through molecular mimicry (74).

Multiple sclerosis is more controversial, and although the etiology of this disease remains unknown it is likely that the trigger for MS is multifactorial. One interesting hypotheses involves a neurotropic infectious agent, possibly a virus, and HERV-K(HML-2) is one candidate in this context (75). Indeed, Tai and Colleagues found HERV-K18 expressing a superantigen in its env gene to be a risk factor for MS (76) and although this observation was made in a very small cohort, it is exciting because expression of HERV-K18 superantigen is also elevated in juvenile RA (77). There is also some evidence that, depending on the population, the LTR sequences of HERVs such as HRES-1 show polymorphisms within MS patient haplotypes while those from non-MS patients are identical without geographic restrictions (78). However, Moyes and Colleagues have published data showing that HERV-K113 and HERV-K115 are not significantly increased in patients with MS compared to the combined parent group $(79,80)$ and their results do not therefore support an association between these particular endogenous retroviruses and MS $(79,81)$. Finally, various groups have reported an association between HERV-K18 polymorphisms and type 1 diabetes $(82,83)$. In summary, a correlation between HERV-K expression and autoimmune disease is neither refuted nor proven. A definite conclusion will need to be based on a great deal more data.

In contrast to the situation with autoimmune diseases, the picture concerning HERV-K expression in malignant diseases is much clearer. As already mentioned, the expression of HERV-K(HML-2) in malignant tissues such as germ cell tumors (GCTs), melanomas, or ovarian cancers is considerably higher than in healthy tissues (5, $6,70,72,84-86)$. A number of malignant diseases suggested to be associated with HERV-K expression are listed in Table 2. HERV-K expression was first observed in GCTs (87-89) and is often associated with the release of HERV-K(HML-2) particles. The frequent induction of an immune response to HERV-K(HML-2) Gag and Env proteins $(90,91)$ is well documented in patients with GCT disease. The presence of antibodies specific for HERV-K(HML2) proteins correlates strongly with the clinical manifestation of GCTs and may therefore be used as a diagnostic and prognostic marker for these types of cancer (92). Interestingly, HERV-K expression in teratocarcinoma cell lines can be further enhanced by androgens (93), although, it is still unknown whether the androgen receptor (AR) binds directly to HERV-K LTRs or acts via other host proteins. Direct binding of other cellular proteins and transcription factors to the HERV-K(HML-2) LTR have already been demonstrated $(94,95)$.

Beside teratocarcinomas HERV-K proteins are expressed in $90 \%$ of epithelial ovarian tumors but at only very low levels, if at all, in healthy tissues or benign tumors (72). Activation of HERV-K expression in ovarian cancer might occur in response to stimulating transcriptional factors that are expressed in malignant ovarian cells (96). Such mechanisms, which lead to hypomethylation and subsequent enhancement of HERV-K transcription, have been already described for HERV-H and HERV-W elements in the ovaries (97-100) and for HERV-K in urothelial cancer and GCTs (101, 102).

Expression of HERV-K in melanomas has been the subject of intense study by many groups $(6,86)$. Both mRNA and Gag, Env, Rec, Np9, and RT proteins have been detected in specimens from primary and metastatic melanoma biopsies and melanoma cell lines but not in melanocytes or normal lymph nodes $(6,86)$. Muster and colleagues even observed retrovirus-like particles consisting of mature forms of Gag and Env and having RT activity (86). About $85 \%$ of malignant melanocytes express HERV-K MEL that is produced by a pseudo-gene incorporated into the HERV$\mathrm{K}$ env gene and which has already been defined as a marker for melanoma risk (103-105). In accordance with the high levels of HERV-K expression, antibodies specific for Env and Gag were detectable in the sera of $16-22 \%$ of melanoma patients but not in those of healthy controls $(6,106)$. Hahn et al. showed in 2008 that the immune response of melanoma patients against HERV$\mathrm{K}$ gene products correlates negatively with their survival (106). In line with existing knowledge about melanoma development, HERV-K expression can be triggered by UV radiation and may therefore be able to accelerate carcinogenesis $(107,108)$.

In addition to teratocarcinomas, ovary tumors, and melanomas, elevated levels of HERV-K(HML-2) env RNA were also detected in breast cancer tissues and gag RNA was found in the peripheral blood cells of leukemia patients as well as in breast and prostate cancers (109-112). The possible influence of steroid hormones on HERV-K activity in both breast cancer and prostate cancer is being discussed, with various groups reporting a stimulating effect of estroprogestin on HERV-K env transcription in breast cancer cells $(110,112,113)$.

It was reported in early 2006 that, in contrast to patients undergoing successful HAART or to seronegative controls, HERV$\mathrm{K}(\mathrm{HML}-2)$ RNA can be found in the plasma of HIV-1 infected individuals whose antiretroviral therapy fails to control virus replication $(114,115)$. Subsequently, it was even possible to observe virus-like particles by electron microscopy and by immunostaining using HERV-K Env and Gag specific antibodies (116). A 
Table 2 | List of malignant diseases that are associated with HERV-K(HML-2) activity.

\begin{tabular}{|c|c|c|c|}
\hline Tissue & Cancer & HERV-K(HML-2) activity & Reference \\
\hline Skin & Melanoma & $\begin{array}{l}\text { Retroviral particles } \\
\text { Enhanced transcription } \\
\text { RT activity } \\
\text { Expression of Env, Rec, Np9 }\end{array}$ & $\begin{array}{l}\text { Buscher et al. (6), Muster et al. (86), Hirschl } \\
\text { et al. (124) }\end{array}$ \\
\hline Testes & $\begin{array}{l}\text { Germ cell tumors, } \\
\text { gonadoblastoma, seminoma }\end{array}$ & $\begin{array}{l}\text { Anti-Gag/Env-Ab } \\
\text { Expression of Rec, Np9 }\end{array}$ & $\begin{array}{l}\text { Boller et al. (87), Kleiman et al. (92), Boller et } \\
\text { al. (125) }\end{array}$ \\
\hline Ovary & $\begin{array}{l}\text { Ovarian clear cell carcinoma; } \\
\text { ovarian epithelial tumors }\end{array}$ & Expression of Gag and Env & $\begin{array}{l}\text { Gotzinger et al. (15), Wang-Johanning et al. } \\
\text { (72), Iramaneerat et al. (126) }\end{array}$ \\
\hline Breast & Breast cancer & $\begin{array}{l}\text { Free viral RNA } \\
\text { RT activity } \\
\text { Virus particles } \\
\text { Specific CTLs }\end{array}$ & $\begin{array}{l}\text { Wang-Johanning et al. (112), } \\
\text { Contreras-Galindo et al. (127), } \\
\text { Wang-Johanning et al. (128) }\end{array}$ \\
\hline Prostate & Prostate cancer & $\begin{array}{l}\text { Enhanced Gag-production due to fusion to } \\
\text { androgen-dependent ETV1 and ETS genes }\end{array}$ & $\begin{array}{l}\text { Tomlins et al. (12), Lamprecht et al. (13), } \\
\text { Ishida et al. (111) }\end{array}$ \\
\hline Blood & Lymphoma & $\begin{array}{l}\text { Free RNA } \\
\text { RT activity } \\
\text { Virus-like particles }\end{array}$ & Contreras-Galindo et al. (127) \\
\hline
\end{tabular}

possible mechanism for preferential HERV-K expression in HIV-1 infected cells could be the interaction between HIV-1 Rev and the Rec response region in HERV-K(HML-2) RNA $(11,117)$ as well as the recently demonstrated susceptibility of the HERV-K (HML-2) transcriptional promoter to HIV-1 Tat (118).

The putative association between HERV-K(HML-2) expression and HIV-1 infection is strengthened by the detection of HERV$\mathrm{K}$ specific cytotoxic T-cells in HIV-1 infected individuals (119). Interestingly, such HERV-specific T-cells are not found in HTLV-1 infected individuals (120), although this latter study cannot completely rule out an involvement of HERV activation in HTLV-1 pathogenesis. HERV-K specific CD8+ T-cells that can recognize and kill cells presenting the cognate peptides as a result of HIVinduced expression of HERV proteins (119) may play an important part in the natural immune response to HIV (121). In contrast to HIV specific CD8+ T-cells that are compromised in their ability to cope with the profound diversity of HIV-1 and subsequent appearance of escape mutants, the HERV proteins remain unchanged throughout the course of infection. Having an unchanging target allows HERV-specific T-cell clones from HIV-1 infected individuals to kill, in vitro at least, human CD4+ cells infected with viruses as diverse as HIV-1, HIV-2, and SIV (122). The stimulation of HERV-specific T-cells may therefore offer a new approach to inducing a broadly specific anti-HIV immune response. Of course, this approach is currently hampered by our limited understanding of HERV antigen expression in different individuals, tissues, and diseases (123).

\section{IMPLICATIONS FOR CANCER DEVELOPMENT}

Whether HERV-K expression is an initiator of cancerous processes or is simply a consequence of malignant degeneration remains a topic of discussion. Many groups have found evidence for the involvement of HERV-K in tumor processes and various hypotheses concerning its potential contribution to oncogenesis have been postulated. These possible mechanisms include the misregulation of oncogenes, protooncogenes, or growth factors by HERV-K LTRs or HERV loci. Several examples of transcriptionally active HERV loci that influence neighboring genes by providing alternative promotors are known $(13,129)$. Hypomethylation often affects HERV-derived solo LTRs that function as alternate promoters, for example the HERV-derived LTR is hypomethylated in B cellderived Hodgkin's lymphoma and is responsible for deregulated expression of the colony-stimulating factor 1 receptor (CSF1R), a protooncogene (13). Another possible mechanism for HERV loci to affect cellular gene transcripts is by the provision of alternative splice and polyadenylation sites [reviewed in Ref. (16)].

A second mechanism of tumor induction/promotion by HERV-K is the inactivation of tumor suppressor genes by de novo insertion or translocation of retroelements within the genome (70, 130). Recombination involving HERV-K sequences might also lead to chromosomal instability and large-scale chromosomal anomalies such as those typically observed in aberrant cells $(131,132)$.

A third mechanism is the expression of HERV proteins such as Rec and Np9 that function as oncogenes or of proteins that induce cell-cell fusion such as Env. It is possible that cell fusions initiated by Env contribute to tumor progression or might even play an important role in metastasis (133). Furthermore, Env is considered to have immunosuppressive properties and may therefore play a role in tumor escape processes (133-135). HERV-K may trigger the pathological processes that lead to melanoma development and contribute to the cellular modifications implicated in melanoma maintenance and progression $(96,136)$. UV radiation, hormone action, or mutating viruses lead to enhanced expression 
of HERV-K proteins such as Env or the HERV-K MEL-antigen that is particularly expressed in melanomas $(96,107,137)$. The HERV-K Env protein is a molecular mimic of the oxygen responsive element binding protein (OREBP), a human nuclear factor that controls the expression of glutathione peroxidase, resulting in reduced production of the enzyme (137). This further increases the toxicity of free radicals that are no longer under proper control and enhances the risk of cancer.

\section{POTENTIAL ONCOGENES: Rec AND Np9}

In recent years evidence has accumulated to indicate a role for the accessory HERV-K(HML-2) protein Rec and for Np9 in tumor development. Rec is a $14.5-\mathrm{kDa}$ protein, translated from a doubly spliced transcript (Figure 2), that mediates the transport of unspliced or partially spliced HERV-K(HML-2) mRNAs from the nucleus into the cytoplasm (11). In 2005, Galli and Co-workers demonstrated that transgenic mice expressing Rec show disturbances in germ cell development and that some animals develop lesions similar to the predecessor lesions of classical seminomas in humans (138). This indicates that HERV-K(HML-2) Rec expression might play a direct role in cell transformation, creating a pre-cancerous state, although the molecular mechanisms and pathways involved remain elusive.

The cellular interaction partners of Rec are also poorly defined, although some have recently been identified. Rec interacts with the promyelocytic leukemia zinc-finger protein (PLZF) that is essential for the self-renewal of spermatogonial stem cells in mice and which may also be involved in certain human leukemias (139142). Transient co-expression of Rec with PLZF interferes with its function as a negative regulator of the $c-m y c$ protooncogene and cells stably transfected with PLZF and Rec show increased cell proliferation (142). Recently, Kaufmann et al. reported that Rec forms trimeric complexes with the testicular zinc-finger protein (TZFP) and the AR (143). These data support the findings of other groups, including our own. Rec interacts directly with the human small glutamine-rich tetratricopeptide repeat-containing protein (hSGT), a co-chaperone and negative regulator of the AR (93, 144). Binding of Rec to the co-chaperone abrogates its ability to bind to the AR and to maintain it in an inactive state (93), which in turn leads to enhanced levels of AR activity. It is interesting that HERV-K transcription (and subsequently Rec expression) can be stimulated by hormones, including androgens, and various steroid hormone-binding sites are predicted to be located within the HERV-K LTR $(89,93,95,113)$.

In contrast to Rec, Np9 has no known physiological function in HERV-K replication. This $9 \mathrm{kDa}$ protein is produced by viruses lacking a 292-bp sequence within the pol-env boundary. Np9,

\section{REFERENCES}

1. Bentvelzen P, Daams JH, Hageman P, Calafat J. Genetic transmission of viruses that incite mammary tumor in mice. Proc Natl Acad Sci U S A (1970) 67(1):377-84. doi:10.1073/pnas. 67.1.377

2. Palmarini M, Mura M, Spencer TE. Endogenous betaretroviruses of sheep: teaching new lessons

whose first 15 amino acids are identical to Env and Rec, is expressed exclusively in various tumor tissues such as breast cancer, GCTs, ovary cancer, and leukemia $(47,145)$. It is therefore important to identify host proteins potentially interacting with $\mathrm{Np} 9$.

$\mathrm{Np}$, like Rec, binds to the PLZF protein, albeit in a different region. Also like Rec, $\mathrm{Np} 9$ is able to abrogate the regulator of the $c$ $m y c$ protooncogene, leading to increased $c-m y c$ transcription that in turn leads to enhanced cell growth and reduced apoptosis (142).

$\mathrm{Np} 9$ has also been shown to interact with the ligand of Numb protein X (LNX), a RING-type E3 ubiquitin ligase that ubiquitylates Numb and marks it for degradation by $26 \mathrm{~S}$ proteasomes (146). Numb is an antagonist of the transcription factor Notch and both proteins regulate the pro-proliferative Ras signaling cascade. Misregulation of this system has been linked to breast cancer, leukemias, and GCTs (147-151). Furthermore, Chen and $\mathrm{Co}$-workers recently reported that $\mathrm{Np} 9$ is a potent viral oncogene in human leukemia (145). This small protein promotes growth of myeloid and lymphoblastic leukemic cells by activation of ERK, AKT, and Notch 1 pathways and by upregulation of $\beta$-catenin. The latter is essential for survival of leukemia stem/progenitor cells.

\section{CONCLUDING REMARISS AND OUTLOOK}

The examples of HERV activity described in this review make it clear that these elements are not simply pieces of "junk DNA" that litter the genome because a mechanism to completely remove an integrated retrovirus from the germ line does not exist. Despite having been discovered in the late 1960s, it appears that many of the intricate evolutionary and physiological roles in health and disease played by the retroviral part of our own genome still remain to be revealed. In addition, many questions concerning the endogenization process, the interplay of coexisting endogenous and exogenous forms, population dynamics, and the fixation of ERVs remain open. The regulation of human genes by HERV-K(HML-2) and other HERV families and the silencing and restriction mechanisms by which the host controls their activities are currently of particular interest.

From a virological point of view, the reconstitution of consensus sequences and expression of original HERV-K(HML-2) proteins have greatly facilitated studies into the functional role of viral proteins in the replication cycle and in cellular processes. This, as well as the increasing availability of whole genome sequences, significantly enriches the exciting and novel field of "paleoretrovirology."

\section{ACKNOWLEDGMENTS}

The authors are indebted to Steve Norley for critical reading of the manuscript and inspiring discussions.

characterization, and comparative genomic distribution of the HERV-K (HML-2) group of human endogenous retroviruses. Retrovirology (2011) 8:90. doi:10.1186/1742-4690-8-90

5. Lower R, Lower J, Frank $\mathrm{H}$, Harzmann R, Kurth R. Human teratocarcinomas cultured in vitro produce unique retrovirus-like viruses. J Gen Virol (1984) 65(Pt 5):887-98. doi:10.1099/ 0022-1317-65-5-887

6. Buscher K, Trefzer U, Hofmann M, Sterry W, Kurth R, Denner J. Expression of human endogenous retrovirus $\mathrm{K}$ in melanomas and melanoma cell lines. Cancer Res (2005) 65(10):4172-80. doi:10.1158/ 0008-5472.CAN-04-2983 
7. Schmitt K, Reichrath J, Roesch A, Meese E, Mayer J. Transcriptional profiling of human endogenous retrovirus group HERV-K(HML2) loci in melanoma. Genome Biol Evol (2013) 5(2):307-28. doi:10. 1093/gbe/evt010

8. Dewannieux M, Harper F, Richaud A, Letzelter C, Ribet D, Pierron G, et al. Identification of an infectious progenitor for the multiplecopy HERV-K human endogenous retroelements. Genome Res (2006) 16(12):1548-56. doi:10. 1101/gr.5565706

9. Lee YN, Bieniasz PD. Reconstitution of an infectious human endogenous retrovirus. PLoS Pathog (2007) 3(1):e10. doi:10.1371/journal.ppat.0030010

10. Macfarlane C, Simmonds P. Allelic variation of HERV-K(HML-2) endogenous retroviral elements in human populations. J Mol Evol (2004) 59(5):642-56. doi:10.1007/ s00239-004-2656-1

11. Magin C, Lower R, Lower J. CORF and RcRE, the Rev/Rex and RRE/RxRE homologues of the human endogenous retrovirus family HTDV/HERV-K. I Virol (1999) 73(11):9496-507.

12. Tomlins SA, Laxman B, Dhanasekaran SM, Helgeson BE, Cao X, Morris DS, et al. Distinct classes of chromosomal rearrangements create oncogenic ETS gene fusions in prostate cancer. Nature (2007) 448(7153):595-9. doi:10.1038/nature06024

13. Lamprecht B, Walter K, Kreher S, Kumar R, Hummel M, Lenze D, et al. Derepression of an endogenous long terminal repeat activates the CSF1R proto-oncogene in human lymphoma. Nat Med (2010) 16(5):571-9. doi:10.1038/ nm.2129 1p following 579,

14. Buzdin A, KovalskayaAlexandrova E, Gogvadze E, Sverdlov E. At least $50 \%$ of human-specific HERV-K (HML2) long terminal repeats serve in vivo as active promoters for host nonrepetitive DNA transcription. $J$ Virol (2006) 80(21):10752-62. doi:10.1128/JVI.00871-06

15. Gotzinger N, Sauter M, Roemer $\mathrm{K}$, Mueller-Lantzsch N. Regulation of human endogenous retrovirus$\mathrm{K}$ Gag expression in teratocarcinoma cell lines and human tumours. J Gen Virol (1996) 77(Pt 12):2983-90. doi:10.1099/ 0022-1317-77-12-2983

16. Cohen CJ, Lock WM, Mager DL. Endogenous retroviral LTRs as promoters for human genes: a critical assessment. Gene (2009) 448(2):105-14 doi:10.1016/j.gene.2009.06.020

17. Conley AB, Miller WJ, Jordan IK. Human cis natural antisense transcripts initiated by transposable elements. Trends Genet (2008) 24(2):53-6. doi:10.1016/j.tig.2007. 11.008

18. Conley AB, Piriyapongsa J, Jordan IK. Retroviral promoters in the human genome. Bioinformatics (2008) 24(14):1563-7. doi:10. 1093/bioinformatics/btn243

19. Gogvadze E, Stukacheva E, Buzdin A, Sverdlov E. Human-specific modulation of transcriptional activity provided by endogenous retroviral insertions. $J$ Virol (2009) 83(12):6098-105. doi:10.1128/JVI.00123-09

20. Vogt PK, Friis RR. An avian leukosis virus related to $\operatorname{RSV}(\mathrm{O})$ : properties and evidence for helper activity. Virology (1971) 43(1):223-34. doi:10.1016/00426822(71)90240-6

21. Weiss RA. The discovery of endogenous retroviruses. Retrovirology (2006) 3:67. doi:10.1186/ 1742-4690-3-S1-S67

22. Weiss RA, Payne LN. The heritable nature of the factor in chicken cells which acts as a helper virus for Rous sarcoma virus. Virology (1971) 45(2):508-15. doi:10.1016/ 0042-6822(71)90351-5

23. Salter DW, Smith EJ, Hughes SH, Wright SE, Crittenden LB. Transgenic chickens: insertion of retroviral genes into the chicken germ line. Virology (1987) 157(1):236-40.

24. Bannert N, Kurth R. The evolutionary dynamics of human endogenous retroviral families. Аnnu Rev Genomics Hum Genet (2006) 7:149-73. doi:10.1146/ annurev.genom.7.080505.115700

25. Belshaw R, Dawson AL, WoolvenAllen J, Redding J, Burt A, Tristem M. Genomewide screening reveals high levels of insertional polymorphism in the human endogenous retrovirus family HERV-K(HML2): implications for present-day activity. J Virol (2005) 79(19):12507-14. doi:10.1128/ JVI.79.19.12507-12514.2005

26. Turner G, Barbulescu M, Su M, Jensen-Seaman MI, Kidd KK, Lenz J. Insertional polymorphisms of full-length endogenous retroviruses in humans. Curr Biol (2001) 11(19):1531-5. doi:10. 1016/S0960-9822(01)00455-9

27. Fiebig U, Hartmann MG, Bannert $N$, Kurth $R$, Denner J.
Transspecies transmission of the endogenous koala retrovirus. $J$ Virol (2006) 80(11):5651-4. doi: 10.1128/JVI.02597-05

28. Tarlinton RE, Meers J, Young PR. Retroviral invasion of the koala genome. Nature (2006) 442(7098):79-81. doi:10.1038/nature04841

29. Shojima T, Hoshino S, Abe M, Yasuda J, Shogen H, Kobayashi T, et al. Construction and characterization of an infectious molecular clone of Koala retrovirus. J Virol (2013) 87(9):5081-8. doi:10.1128/ JVI.01584-12

30. Bonnaud B, Bouton O, Oriol G, Cheynet V, Duret L, Mallet F. Evidence of selection on the domesticated ERVWE1 env retroviral element involved in placentation. Mol Biol Evol (2004) 21(10):1895-901. doi:10.1093/ molbev/msh206

31. Jern P, Sperber GO, Blomberg $\mathrm{J}$. Use of endogenous retroviral sequences (ERVs) and structural markers for retroviral phylogenetic inference and taxonomy. Retrovirology (2005) 2:50. doi:10.1186/ 1742-4690-2-S1-S50

32. Ono $M$, Yasunaga $T$, Miyata $T$, Ushikubo H. Nucleotide sequence of human endogenous retrovirus genome related to the mouse mammary tumor virus genome. $J$ Virol (1986) 60(2):589-98.

33. Franklin GC, Chretien S, Hanson IM, Rochefort H, May FE, Westley BR. Expression of human sequences related to those of mouse mammary tumor virus. $J$ Virol (1988) 62(4):1203-10.

34. Medstrand P, Blomberg J. Characterization of novel reverse transcriptase encoding human endogenous retroviral sequences similar to type $\mathrm{A}$ and type $\mathrm{B}$ retroviruses: differential transcription in normal human tissues. J Virol (1993) 67(11):6778-87.

35. Andersson ML, Lindeskog $\mathrm{M}$, Medstrand P, Westley B, May F, Blomberg J. Diversity of human endogenous retrovirus class II-like sequences. J Gen Virol (1999) 80(Pt 1):255-60.

36. Mayer J, Meese E. Human endogenous retroviruses in the primate lineage and their influence on host genomes. Cytogenet Genome Res (2005) 110(1-4):448-56. doi:10. $1159 / 000084977$

37. Seifarth W, Baust C, Murr A, Skladny H, Krieg-Schneider F, Blusch J, et al. Proviral structure, chromosomal location, and expression of HERV-K-T47D, a novel human endogenous retrovirus derived from T47D particles. J Virol (1998) 72(10):8384-91.

38. Mager DL, Medstrand P. Retroviral repeat sequences. In: Cooper D, editor. Nature Encyclopedia of the Human Genome. London: Nature Publishing Group (2003). p. 57-63.

39. Johnson WE, Coffin JM. Constructing primate phylogenies from ancient retrovirus sequences. Proc Natl Acad Sci U S A (1999) 96(18):10254-60. doi:10.1073/pnas.96.18.10254

40. Lavie L, Maldener E, Brouha B, Meese EU, Mayer J. The human L1 promoter: variable transcription initiation sites and a major impact of upstream flanking sequence on promoter activity. Genome Res (2004) 14(11):2253-60. doi: 10.1101/gr.2745804

41. Flockerzi A, Burkhardt S, Schempp W, Meese E, Mayer J. Human endogenous retrovirus HERV-K14 families: status, variants, evolution, and mobilization of other cellular sequences. J Virol (2005) 79(5):2941-9. doi:10.1128/JVI.79. 5.2941-2949.2005

42. Ono M. Molecular cloning and long terminal repeat sequences of human endogenous retrovirus genes related to types $\mathrm{A}$ and $\mathrm{B}$ retrovirus genes. J Virol (1986) 58(3):937-44.

43. Mayer J, Meese EU. The human endogenous retrovirus family HERV-K(HML-3). Genomics (2002) 80(3):331-43. doi:10.1006/geno.2002.6839

44. Medstrand P, Mager DL, Yin H, Dietrich U, Blomberg J. Structure and genomic organization of a novel human endogenous retrovirus family: HERV-K (HML6). J Gen Virol (1997) $78(\mathrm{Pt}$ 7):1731-44.

45. Yin $H$, Medstrand $P$, Kristofferson A, Dietrich U, Aman P, Blomberg J. Characterization of human MMTV-like (HML) elements similar to a sequence that was highly expressed in a human breast cancer: further definition of the HML-6 group. Virology (1999) 256(1):22-35. doi:10.1006/ viro.1998.9587

46. Tassabehji M, Strachan T, Anderson M, Campbell RD, Collier $S$, Lako M. Identification of a novel family of human endogenous retroviruses and characterization of one family member, HERV-K(C4), located in the complement C4 gene cluster. Nucleic 
Acids Res (1994) 22(24):5211-7. doi:10.1093/nar/22.24.5211

47. Armbruester V, Sauter M, Krautkraemer E, Meese E, Kleiman $\mathrm{A}$, Best $\mathrm{B}$, et al. A novel gene from the human endogenous retrovirus $\mathrm{K}$ expressed in transformed cells. Clin Cancer Res (2002) 8(6):1800-7.

48. Lower R, Tonjes RR, Korbmacher C, Kurth R, Lower J. Identification of a Rev-related protein by analysis of spliced transcripts of the human endogenous retroviruses HTDV/HERV-K. J Virol (1995) 69(1):141-9.

49. George M, Schwecke T, Beimforde N, Hohn O, Chudak C, Zimmermann A, et al. Identification of the protease cleavage sites in a reconstituted Gag polyprotein of an HERV-K(HML-2) element. Retrovirology (2011) 8:30. doi:10.1186/ 1742-4690-8-30

50. Dewannieux M, Blaise S, Heidmann T. Identification of a functional envelope protein from the HERV-K family of human endogenous retroviruses. J Virol (2005) 79(24):15573-7. doi:10.1128/JVI. 79.24.15573-15577.2005

51. Hanke K, Kramer P, Seeher S, Beimforde N, Kurth R, Bannert N. Reconstitution of the ancestral glycoprotein of human endogenous retrovirus $\mathrm{k}$ and modulation of its functional activity by truncation of the cytoplasmic domain. $J$ Virol (2009) 83(24):12790-800. doi:10.1128/JVI.01368-09

52. Mayer J, Meese EU. Presence of dUTPase in the various human endogenous retrovirus $\mathrm{K}$ (HERVK) families. J Mol Evol (2003) 57(6):642-9. doi:10.1007/s00239003-2514-6

53. Lee YN, Malim MH, Bieniasz PD. Hypermutation of an ancient human retrovirus by APOBEC3G. JVirol (2008) 82(17):8762-70. doi: 10.1128/JVI.00751-08

54. Beimforde N, Hanke K, Ammar I, Kurth R, Bannert N. Molecular cloning and functional characterization of the human endogenous retrovirus K113. Virology (2008) 371(1):216-25. doi:10.1016/j.virol.2007.09.036

55. Paprotka T, Delviks-Frankenberry KA, Cingoz O, Martinez A, Kung HJ, Tepper CG, et al. Recombinant origin of the retrovirus XMRV. Science (2011) 333(6038):97-101. doi:10.1126/science.1205292

56. Young GR, Eksmond U, Salcedo R, Alexopoulou L, Stoye JP, Kassiotis G. Resurrection of endogenous retroviruses in antibody-deficient mice. Nature (2012) 491(7426):774-8. doi:10.1038/nature11599

57. King MC, Wilson AC. Evolution at two levels in humans and chimpanzees. Science (1975) 188(4184):107-16. doi:10.1126/science.1090005

58. Ting CN, Rosenberg MP, Snow CM, Samuelson LC, Meisler MH. Endogenous retroviral sequences are required for tissue-specific expression of a human salivary amylase gene. Genes Dev (1992) 6(8):1457-65.

59. Mi S, Lee X, Li X, Veldman GM, Finnerty H, Racie L, et al. Syncytin is a captive retroviral envelope protein involved in human placental morphogenesis. Nature (2000) 403(6771):785-9. doi:10. $1038 / 35001608$

60. Blaise S, de Parseval N, Benit L, Heidmann T. Genomewide screening for fusogenic human endogenous retrovirus envelopes identifies syncytin 2, a gene conserved on primate evolution. Proc Natl Acad Sci U S A (2003) 100(22):13013-8. doi:10.1073/ pnas. 2132646100

61. Schlecht-Louf G, Renard M, Mangeney $\mathrm{M}$, Letzelter $\mathrm{C}$, Richaud A, Ducos B, et al. Retroviral infection in vivo requires an immune escape virulence factor encrypted in the envelope protein of oncoretroviruses. Proc Natl Acad Sci U S A (2010) 107(8):3782-7. doi:10. 1073/pnas.0913122107

62. Dupressoir A, Marceau G, Vernochet C, Benit L, Kanellopoulos C, Sapin V, et al. Syncytin$A$ and syncytin-B, two fusogenic placenta-specific murine envelope genes of retroviral origin conserved in Muridae. Proc Natl Acad Sci U S A (2005) 102(3):725-30. doi:10.1073/pnas.0406509102

63. Dupressoir A, Vernochet C, Bawa O, Harper F, Pierron G, Opolon $\mathrm{P}$, et al. Syncytin-A knockout mice demonstrate the critical role in placentation of a fusogenic, endogenous retrovirus-derived, envelope gene. Proc Natl Acad Sci U S A (2009) 106(29):12127-32. doi:10. 1073/pnas.0902925106

64. Dupressoir A, Lavialle C, Heidmann T. From ancestral infectious retroviruses to bona fide cellular genes: role of the captured syncytins in placentation. Placenta (2012) 33(9):663-71. doi:10.1016/ j.placenta.2012.05.005

65. Spencer TE, Mura M, Gray CA, Griebel PJ, Palmarini M. Receptor usage and fetal expression of ovine endogenous betaretroviruses: implications for coevolution of endogenous and exogenous retroviruses. J Virol (2003) 77(1):749-53. doi:10.1128/JVI.77. 1.749-753.2003

66. Arnaud F, Caporale M, Varela M, Biek R, Chessa B, Alberti A, et al. A paradigm for virus-host coevolution: sequential counteradaptations between endogenous and exogenous retroviruses. PLoS Pathog (2007) 3(11):e170. doi:10. 1371/journal.ppat.0030170

67. Best S, Le Tissier P, Towers G, Stoye JP. Positional cloning of the mouse retrovirus restriction gene Fv1. Nature (1996) 382(6594):826-9. doi:10.1038/382826a0

68. Oja M, Peltonen J, Blomberg J, Kaski S. Methods for estimating human endogenous retrovirus activities from EST databases. BMC Bioinformatics (2007) 8(Suppl 2):S11. doi:10.1186/14712105-8-S2-S1 1

69. Perot P, Mugnier N, Montgiraud C, Gimenez J, Jaillard M, Bonnaud B, et al. Microarray-based sketches of the HERV transcriptome landscape. PLoS One (2012) 7(6):e40194. doi:10.1371/journal. pone. 0040194

70. Kurth R, Bannert N. Beneficial and detrimental effects of human endogenous retroviruses. Int $J$ Cancer (2010) 126(2):306-14. doi: $10.1002 / \mathrm{ijc} .24902$

71. Kammerer U, Germeyer A, Stengel S, Kapp M, Denner J. Human endogenous retrovirus $\mathrm{K}$ (HERV$\mathrm{K})$ is expressed in villous and extravillous cytotrophoblast cells of the human placenta. J Reprod Immunol (2011) 91(1-2):1-8. doi: 10.1016/j.jri.2011.06.102

72. Wang-Johanning F, Liu J, Rycaj $\mathrm{K}$, Huang $\mathrm{M}$, Tsai $\mathrm{K}$, Rosen DG, et al. Expression of multiple human endogenous retrovirus surface envelope proteins in ovarian cancer. Int $J$ Cancer (2007) 120(1):81-90. doi:10.1002/ ijc. 22256

73. Andersson AC, Venables PJ, Tonjes RR, Scherer J, Eriksson L, Larsson E. Developmental expression of HERV-R (ERV3) and HERV-K in human tissue. Virology (2002) 297(2):220-5. doi:10.1006/ viro.2002.1428

74. Freimanis G, Hooley P, Ejtehadi HD, Ali HA, Veitch A, Rylance PB, et al. A role for human endogenous retrovirus-K (HML-2) in rheumatoid arthritis: investigating mechanisms of pathogenesis. Clin Exp Immunol (2010)
160(3):340-7. doi:10.1111/j.13652249.2010.04110.x

75. Tselis A. Evidence for viral etiology of multiple sclerosis. Semin Neurol (2011) 31(3):307-16. doi:10.1055/ s-0031-1287656

76. Tai AK, O’Reilly EJ, Alroy KA, Simon KC, Munger KL, Huber BT, et al. Human endogenous retrovirus-K18 Env as a risk factor in multiple sclerosis. Mult Scler (2008) 14(9):1175-80. doi: $10.1177 / 1352458508094641$

77. Sicat J, Sutkowski N, Huber BT. Expression of human endogenous retrovirus HERV-K18 superantigen is elevated in juvenile rheumatoid arthritis. J Rheumatol (2005) 32(9):1821-31.

78. Clausen J. Endogenous retroviruses and MS: using ERVs as disease markers. Int MS J (2003) 10(1):22-8

79. Moyes DL, Goris A, Ban M, Compston A, Griffiths DJ, Sawcer S, et al. HERV-K113 is not associated with multiple sclerosis in a large familybased study. AIDS Res Hum Retroviruses (2008) 24(3):363-5. doi:10. 1089/aid.2007.0196

80. Moyes DL, Martin A, Sawcer S, Temperton N, Worthington J, Griffiths DJ, et al. The distribution of the endogenous retroviruses HERV-K113 and HERV-K115 in health and disease. Genomics (2005) 86(3):337-41. doi:10.1016/ j.ygeno.2005.06.004

81. Antony JM, Deslauriers AM, Bhat RK, Ellestad KK, Power C. Human endogenous retroviruses and multiple sclerosis: innocent bystanders or disease determinants? Biochim Biophys Acta (2011) 1812(2):162-76 doi:10.1016/j.bbadis.2010.07.016

82. Conrad B, Weissmahr RN, Boni J, Arcari R, Schupbach J, Mach B. A human endogenous retroviral superantigen as candidate autoimmune gene in type I diabetes. Cell (1997) 90(2):303-13. doi:10.1016/ S0092-8674(00)80338-4

83. Marguerat S, Wang WY, Todd JA, Conrad B. Association of human endogenous retrovirus K-18 polymorphisms with type 1 diabetes. Diabetes (2004) 53(3):852-4. doi: 10.2337/diabetes.53.3.852

84. Buscher K, Hahn S, Hofmann M, Trefzer U, Ozel M, Sterry W, et al. Expression of the human endogenous retrovirus- $\mathrm{K}$ transmembrane envelope, Rec and Np9 proteins in melanomas and melanoma cell lines. Melanoma Res (2006) 16(3):223-34. doi:10.1097/01.cmr. 0000215031.07941.ca 
85. Herbst H, Sauter M, MuellerLantzsch N. Expression of human endogenous retrovirus $\mathrm{K}$ elements in germ cell and trophoblastic tumors. Am J Pathol (1996) 149(5):1727-35.

86. Muster T, Waltenberger A, Grassauer A, Hirschl S, Caucig P, Romirer I, et al. An endogenous retrovirus derived from human melanoma cells. Cancer Res (2003) 63(24):8735-41.

87. Boller K, Konig H, Sauter M, Mueller-Lantzsch $\mathrm{N}$, Lower R, Lower $\mathrm{J}$, et al. Evidence that HERV-K is the endogenous retrovirus sequence that codes for the human teratocarcinoma-derived retrovirus HTDV. Virology (1993) 196(1):349-53. doi:10.1006/viro. 1993.1487

88. Kurth R Löwer R, Löwer J, Harzmann R, Pfeiffer R, Schmidt $\mathrm{GC}$, et al. Oncornavirus synthesis in human teratocarcinoma cultures and an increased antiviral immune reactivity in corresponding patients. In: Essex M, Todaro GJ, zur Hausen H, editors. Viruses in Naturally Occurring Cancers. New York: Cold Spring Harbor Laboratory (1980). p. 835-46.

89. Ono M, Kawakami M, Ushikubo H. Stimulation of expression of the human endogenous retrovirus genome by female steroid hormones in human breast cancer cell line T47D. J Virol (1987) 61(6):2059-62.

90. Goedert JJ, Sauter ME, Jacobson LP, Vessella RL, Hilgartner MW, Leitman SF, et al. High prevalence of antibodies against HERV-K10 in patients with testicular cancer but not with AIDS. Cancer Epidemiol Biomarkers Prev (1999) 8(4 Pt 1):293-6.

91. Sauter M, Schommer S, Kremmer E, Remberger K, Dolken G, Lemm I, et al. Human endogenous retrovirus K10: expression of Gag protein and detection of antibodies in patients with seminomas. J Virol (1995) 69(1):414-21.

92. Kleiman A, Senyuta N, Tryakin A, Sauter M, Karseladze A, Tjulandin S, et al. HERV-K(HML-2) GAG/ENV antibodies as indicator for therapy effect in patients with germ cell tumors. Int J Cancer (2004) 110(3):459-61. doi:10. 1002/ijc. 11649

93. Hanke K, Chudak C, Kurth $\mathrm{R}$, Bannert N. The Rec protein of HERV-K(HML-2) upregulates androgen receptor activity by binding to the human small glutamine-rich tetratricopeptide repeat protein (hSGT). Int J Cancer (2013) 132(3):556-67. doi:10. $1002 /$ ijc. 27693

94. Knossl M, Lower R, Lower J. Expression of the human endogenous retrovirus HTDV/HERV-K is enhanced by cellular transcription factor YY1. J Virol (1999) 73(2):1254-61.

95. Manghera M, Douville RN. Endogenous retrovirus- $\mathrm{K}$ promoter: a landing strip for inflammatory transcription factors? Retrovirology (2013) 10:16. doi:10.1186/1742-4690-10-16

96. Cegolon L, Salata C, Weiderpass E, Vineis P, Palu G, Mastrangelo G. Human endogenous retroviruses and cancer prevention: evidence and prospects. BMC Cancer (2013) 13:4. doi:10.1186/1471-2407-13-4

97. de Parseval N, Alkabbani H, Heidmann $\mathrm{T}$. The long terminal repeats of the HERV-H human endogenous retrovirus contain binding sites for transcriptional regulation by the Myb protein. J Gen Virol (1999) 80(Pt 4):841-5.

98. Lee WJ, Kwun HJ, Kim HS, Jang KL. Activation of the human endogenous retrovirus W long terminal repeat by herpes simplex virus type 1 immediate early protein 1. Mol Cells (2003) 15(1):75-80.

99. Menendez L, Benigno BB, McDonald JF. L1 and HERV-W retrotransposons are hypomethylated in human ovarian carcinomas. $\mathrm{Mol}$ Cancer (2004) 3:12. doi:10.1186/ 1476-4598-3-12

100. Sjottem E, Anderssen S, Johansen $\mathrm{T}$. The promoter activity of long terminal repeats of the HERV-H family of human retrovirus-like elements is critically dependent on $\mathrm{Sp} 1$ family proteins interacting with a GC/GT box located immediately 3' to the TATA box. J Virol (1996) 70(1):188-98.

101. Florl AR, Lower R, Schmitz-Drager BJ, Schulz WA. DNA methylation and expression of LINE-1 and HERV-K provirus sequences in urothelial and renal cell carcinomas. Br J Cancer (1999) 80(9):1312-21. doi:10.1038/sj.bjc. 6690524

102. Lavie L, Kitova M, Maldener E, Meese E, Mayer J. CpG methylation directly regulates transcriptional activity of the human endogenous retrovirus family HERV-K(HML-2). J Virol (2005) 79(2):876-83. doi:10.1128/ JVI.79.2.876-883.2005

103. Grange JM, Krone B, Kolmel KF, Mastrangelo G. Can prior vaccinations against certain infections confer protection against developing melanoma? Med J Aust (2009) 191(9):478-9.

104. Kolmel KF, Gefeller O, Haferkamp B. Febrile infections and malignant melanoma: results of a case-control study. Melanoma Res (1992) 2(3):207-11. doi:10.1097/ 00008390-199209000-00009

105. Schiavetti F, Thonnard J, Colau D, Boon T, Coulie PG. A human endogenous retroviral sequence encoding an antigen recognized on melanoma by cytolytic $\mathrm{T}$ lymphocytes. Cancer Res (2002) 62(19):5510-6.

106. Hahn S, Ugurel S, Hanschmann KM, Strobel H, Tondera C, Schadendorf D, et al. Serological response to human endogenous retrovirus $\mathrm{K}$ in melanoma patients correlates with survival probability. AIDS Res Hum Retroviruses (2008) 24(5):717-23. doi:10.1089/ aid.2007.0286

107. Reiche J, Pauli G, Ellerbrok H. Differential expression of human endogenous retrovirus $\mathrm{K}$ transcripts in primary human melanocytes and melanoma cell lines after UV irradiation. Melanoma Res (2010) 20(5):435-40. doi:10.1097/CMR 0b013e32833c1b5d

108. Schanab O, Humer J, Gleiss A, Mikula M, Sturlan S, Grunt S, et al. Expression of human endogenous retrovirus $\mathrm{K}$ is stimulated by ultraviolet radiation in melanoma. Pigment Cell Melanoma Res (2011) 24(4):656-65.

109. Depil S, Roche C, Dussart P, Prin L. Expression of a human endogenous retrovirus, HERV-K, in the blood cells of leukemia patients. Leukemia (2002) 16(2):254-9. doi: 10.1038/sj.leu.2402355

110. Ejthadi HD, Martin JH, Junying J, Roden DA, Lahiri M, Warren $\mathrm{P}$, et al. A novel multiplex RTPCR system detects human endogenous retrovirus$\mathrm{K}$ in breast cancer. Arch Virol (2005) 150(1):177-84. doi:10.1007/s00705-004-0378-8

111. Ishida T, Obata Y, Ohara N, Matsushita $\mathrm{H}$, Sato $\mathrm{S}$, Uenaka A, et al. Identification of the HERV-K gag antigen in prostate cancer by SEREX using autologous patient serum and its immunogenicity. Cancer Immun (2008) 8:15.

112. Wang-Johanning F, Frost AR, Jian B, Epp L, Lu DW, Johanning GL. Quantitation of HERV-K env gene expression and splicing in human breast cancer. Oncogene
(2003) 22(10):1528-35. doi:10. 1038/sj.onc. 1206241

113. Golan M, Hizi A, Resau JH, Yaal-Hahoshen N, Reichman $\mathrm{H}$, Keydar I, et al. Human endogenous retrovirus (HERV-K) reverse transcriptase as a breast cancer prognostic marker. Neoplasia (2008) 10(6):521-33.

114. Contreras-Galindo R, Gonzalez M, Almodovar-Camacho S, GonzalezRamirez S, Lorenzo E, Yamamura Y. A new real-time-RT-PCR for quantitation of human endogenous retroviruses type $\mathrm{K}$ (HERVK) RNA load in plasma samples: increased HERV-K RNA titers in HIV-1 patients with HAART nonsuppressive regimens. J Virol Methods (2006) 136(1-2):51-7. doi:10. 1016/j.jviromet.2006.03.029

115. Contreras-Galindo R, Kaplan $\mathrm{MH}$, Markovitz DM, Lorenzo E, Yamamura Y. Detection of HERV$\mathrm{K}$ (HML-2) viral RNA in plasma of HIV type 1-infected individuals. AIDS Res Hum Retroviruses (2006) 22(10):979-84. doi: 10.1089/aid.2006.22.979

116. Contreras-Galindo R, Kaplan MH, Contreras-Galindo AC, GonzalezHernandez MJ, Ferlenghi I, Giusti $F$, et al. Characterization of human endogenous retroviral elements in the blood of HIV1-infected individuals. J Virol (2012) 86(1):262-76. doi:10.1128/ JVI.00602-11

117. Yang J, Bogerd HP, Peng S, Wiegand $\mathrm{H}$, Truant R, Cullen BR. An ancient family of human endogenous retroviruses encodes a functional homolog of the HIV-1 Rev protein. Proc Natl Acad Sci U S A (1999) 96(23):13404-8. doi:10. 1073/pnas.96.23.13404

118. Gonzalez-Hernandez MJ, Swanson MD, Contreras-Galindo R, Cookinham S, King SR, Noel RJ Jr, et al. Expression of human endogenous retrovirus type $\mathrm{K}$ (HML-2) is activated by the Tat protein of HIV1. J Virol (2012) 86(15):7790-805. doi:10.1128/JVI.07215-11

119. Garrison KE, Jones RB, Meiklejohn DA, Anwar N, Ndhlovu LC, Chapman JM, et al. T cell responses to human endogenous retroviruses in HIV-1 infection. PLoS Pathog (2007) 3(11):e165. doi:10.1371/journal.ppat.0030165

120. Jones RB, Leal FE, Hasenkrug AM, Segurado AC, Nixon DF, Ostrowski $\mathrm{MA}$, et al. Human endogenous retrovirus $\mathrm{K}(\mathrm{HML}-2) \mathrm{Gag}$ and Env specific $\mathrm{T}$-cell responses are not detected in HTLV-I-infected subjects using standard peptide 
screening methods. J Negat Results Biomed (2013) 12:3. doi:10.1186/ 1477-5751-12-3

121. SenGupta D, Tandon R, Vieira RG, Ndhlovu LC, LownHecht R, Ormsby CE, et al. Strong human endogenous retrovirus-specific $\mathrm{T}$ cell responses are associated with control of HIV-1 in chronic infection. $J$ Virol (2011) 85(14):6977-85. doi:10.1128/JVI.00179-11

122. Jones RB, Garrison KE, Mujib S, Mihajlovic V, Aidarus N, Hunter DV, et al. HERV-K-specific T cells eliminate diverse HIV-1/2 and SIV primary isolates. $J$ Clin Invest (2012) 122(12):4473-89. doi:10. 1172/JCI64560

123. van der Kuyl AC. HIV infection and HERV expression: a review. Retrovirology (2012) 9:6. doi:10. 1186/1742-4690-9-6

124. Hirschl S, Schanab O, Seppele $\mathrm{H}$, Waltenberger $\mathrm{A}$, Humer $\mathrm{J}$, Wolff $\mathrm{K}$, et al. Sequence variability of retroviral particles derived from human melanoma cells melanoma-associated retrovirus. Virus Res (2007) 123(2):211-5. doi:10.1016/j.virusres.2006.08.010

125. Boller K, Schonfeld K, Lischer S, Fischer N, Hoffmann A, Kurth R, et al. Human endogenous retrovirus HERV-K113 is capable of producing intact viral particles. $J$ Gen Virol (2008) 89(Pt 2):567-72. doi:10.1099/vir.0.83534-0

126. Iramaneerat K, Rattanatunyong P, Khemapech N, Triratanachat S, Mutirangura A. HERV-K hypomethylation in ovarian clear cell carcinoma is associated with a poor prognosis and platinum resistance. Int J Gynecol Cancer (2011) 21(1):51-7. doi:10.1097/ IGC.0b013e3182021cla

127. Contreras-Galindo R, Kaplan MH, Leissner P, Verjat T, Ferlenghi I, Bagnoli F, et al. Human endogenous retrovirus $\mathrm{K}$ (HML-2) elements in the plasma of people with lymphoma and breast cancer. J Virol (2008) 82(19):9329-36. doi:10.1128/JVI.00646-08

128. Wang-Johanning F, Radvanyi L, Rycaj K, Plummer JB, Yan P, Sastry $\mathrm{KJ}$, et al. Human endogenous retrovirus $\mathrm{K}$ triggers an antigen-specific immune response in breast cancer patients. Cancer Res (2008) 68(14):5869-77. doi:10. 1158/0008-5472.CAN-07-6838

129. Dunn CA, Medstrand P, Mager DL. An endogenous retroviral long terminal repeat is the dominant promoter for human betal,3galactosyltransferase 5 in the colon. Proc Natl Acad Sci U S A (2003) 100(22):12841-6. doi:10. 1073/pnas.2134464100

130. Ruprecht K, Mayer J, Sauter M, Roemer K, Mueller-Lantzsch N. Endogenous retroviruses and cancer. Cell Mol Life Sci (2008) 65(21):3366-82. doi:10.1007/s00018-008-8496-1

131. Mullins CS, Linnebacher M. Human endogenous retroviruses and cancer: causality and therapeutic possibilities. World J Gastroenterol (2012) 18(42):6027-35. doi:10.3748/wjg.v18.i42.6027

132. Romanish MT, Cohen CJ, Mager DL. Potential mechanisms of endogenous retroviral-mediated genomic instability in human cancer. Semin Cancer Biol (2010) 20(4):246-53. doi:10.1016/j. semcancer.2010.05.005

133. Oricchio E, Sciamanna I, Beraldi R, Tolstonog GV, Schumann GG, Spadafora C. Distinct roles for LINE-1 and HERV-K retroelements in cell proliferation, differentiation and tumor progression. Oncogene (2007) 26(29):4226-33. doi:10.1038/sj.onc.1210214

134. Mangeney M, Pothlichet J, Renard M, Ducos B, Heidmann T. Endogenous retrovirus expression is required for murine melanoma tumor growth in vivo. Cancer Res (2005) 65(7):2588-91. doi:10. 1158/0008-5472.CAN-04-4231

135. Singh S, Kaye S, Gore ME, McClure MO, Bunker CB. The role of human endogenous retroviruses in melanoma. Br J Dermatol (2009) 161(6):1225-31. doi:10. 1111/j.1365-2133.2009.09415.x

136. Serafino A, Balestrieri E, Pierimarchi P, Matteucci C, Moroni G, Oricchio E, et al. The activation of human endogenous retrovirus $\mathrm{K}$ (HERV-K) is implicated in melanoma cell malignant transformation. Exp Cell Res (2009) 315(5):849-62. doi:10. 1016/i.yexcr.2008.12.023

137. Krone B, Kolmel KF, Henz BM, Grange JM. Protection against melanoma by vaccination with Bacille Calmette-Guerin (BCG) and/or vaccinia: an epidemiologybased hypothesis on the nature of a melanoma risk factor and its immunological control. Eur J Cancer (2005) 41(1):104-17. doi:10. 1016/j.ejca.2004.08.010

138. Galli UM, Sauter M, Lecher B, Maurer S, Herbst H, Roemer K, et al. Human endogenous retrovirus rec interferes with germ cell development in mice and may cause carcinoma in situ, the predecessor lesion of germ cell tumors. Oncogene (2005) 24(19):3223-8. doi:10. 1038/sj.onc. 1208543

139. Boese A, Sauter M, Galli U, Best B, Herbst H, Mayer J, et al. Human endogenous retrovirus protein cORF supports cell transformation and associates with the promyelocytic leukemia zinc finger protein. Oncogene (2000) 19(38):4328-36. doi:10.1038/sj.onc.1203794

140. Buaas FW, Kirsh AL, Sharma M, McLean DJ, Morris JL, Griswold MD, et al. Plzf is required in adult male germ cells for stem cell self-renewal. Nat Genet (2004) 36(6):647-52. doi:10.1038/ ng1366

141. Costoya JA, Hobbs RM, Barna M, Cattoretti G, Manova K, Sukhwani $M$, et al. Essential role of Plzf in maintenance of spermatogonial stem cells. Nat Genet (2004) 36(6):653-9. doi:10.1038/ng1367

142. Denne M, Sauter M, Armbruester V, Licht JD, Roemer K, MuellerLantzsch N. Physical and functional interactions of human endogenous retrovirus proteins $\mathrm{Np} 9$ and rec with the promyelocytic leukemia zinc finger protein. JVirol (2007) 81(11):5607-16. doi: 10.1128/JVI.02771-06

143. Kaufmann S, Sauter M, Schmitt M, Baumert B, Best B, Boese A, et al. Human endogenous retrovirus protein Rec interacts with the testicular zinc-finger protein and androgen receptor. J Gen Virol (2010) 91(Pt 6):1494-502. doi:10. 1099/vir.0.014241-0

144. Buchanan G, Ricciardelli C, Harris JM, Prescott J, Yu ZC, Jia L, et al. Control of androgen receptor signaling in prostate cancer by the cochaperone small glutamine rich tetratricopeptide repeat containing protein alpha. Cancer Res (2007) 67(20):10087-96. doi:10.1158/ 0008-5472.CAN-07-1646

145. Chen T, Meng Z, Gan Y, Wang X, $\mathrm{Xu} F, \mathrm{Gu} Y$, et al. The viral oncogene Np9 acts as a critical molecular switch for co-activating betacatenin, ERK, Akt and Notchl and promoting the growth of human leukemia stem/progenitor cells. Leukemia (2013) 27(7):1469-78. doi:10.1038/leu.2013.8

146. Armbruester V, Sauter M, Roemer K, Best B, Hahn S, Nty A, et al. Np9 protein of human endogenous retrovirus $\mathrm{K}$ interacts with ligand of numb protein X. J Virol (2004) 78(19):10310-9. doi:10.1128/JVI. 78.19.10310-10319.2004
147. Adamah DJ, Gokhale PJ, Eastwood DJ, Rajpert De-Meyts E, Goepel J, Walsh JR, et al. Dysfunction of the mitotic:meiotic switch as a potential cause of neoplastic conversion of primordial germ cells. Int J Androl (2006) 29(1):219-27. doi:10.1111/j.13652605.2005.00569.x

148. Beverly LJ, Capobianco AJ. Perturbation of Ikaros isoform selection by MLV integration is a cooperative event in Notch(IC)-induced $\mathrm{T}$ cell leukemogenesis. Cancer Cell (2003) 3(6):551-64. doi:10.1016/ S1535-6108(03)00137-5

149. Callahan R, Raafat A. Notch signaling in mammary gland tumorigenesis. J Mammary Gland Biol Neoplasia (2001) 6(1):23-36. doi:10. 1023/A:1009512414430

150. Hayashi T, Kageyama Y, Ishizaka K, Xia G, Kihara K, Oshima H. Requirement of Notch 1 and its ligand jagged 2 expressions for spermatogenesis in rat and human testes. J Androl (2001) 22(6):999-1011.

151. Hayashi T, Yamada T, Kageyama Y, Kihara K. Expression failure of the notch signaling system is associated with the pathogenesis of testicular germ cell tumor. Tumour Biol (2004) 25(3):99-105. doi:10. $1159 / 000079140$

Conflict of Interest Statement: The authors declare that the research was conducted in the absence of any commercial or financial relationships that could be construed as a potential conflict of interest.

Received: 19 July 2013; paper pending published: 11 August 2013; accepted: 05 September 2013; published online: 20 September 2013.

Citation: Hohn $O$, Hanke $K$ and Bannert $N$ (2013) HERV-K(HML-2), the best preserved family of HERVs: endogenization, expression, and implications in health and disease. Front. Oncol. 3:246. doi: 10.3389/fonc.2013.00246

This article was submitted to Molecular and Cellular Oncology, a section of the journal Frontiers in Oncology.

Copyright (c) 2013 Hohn, Hanke and Bannert. This is an open-access article distributed under the terms of the Creative Commons Attribution License (CC $B Y$ ). The use, distribution or reproduction in other forums is permitted, provided the original author(s) or licensor are credited and that the original publication in this journal is cited, in accordance with accepted academic practice. No use, distribution or reproduction is permitted which does not comply with these terms. 